\title{
Compound Odontoma
}

National Cancer Institute

\section{Source}

National Cancer Institute. Compound Odontoma. NCI Thesaurus. Code C3711.

A benign, slow growing, and painless hamartomatous tumor occurring in tooth-bearing areas of the jaws. It usually affects children and adolescents. It is characterized by the presence of tooth-like structures. T reatment consists of local excision. Recurrences have not been reported. 